\title{
Direitos humanos e relações de gênero: Um olhar interdisciplinar
}

Cássia Quelho Tavares

\section{Introdução}

Embora sejam dois assuntos distintos estes se encontram. Para tratarmos das questões de gênero devemos recorrer aos fundamentos dos direitos humanos. Muitas são as dificuldades na compreensão e na articulação que permeiam as relações de gênero.

Esta comunicação, de caráter interdisciplinar, procurará trazer à reflexão os direitos humanos e as implicações do mesmo nas relações de gênero, sobretudo acerca das questões que envolvem a mulher, grupo ainda minoritário nas decisões e nos direitos sociais. Para este diálogo-articulação a teologia será a base fundamental a partir da Ética Cristã.

\section{Cidadania e direitos humanos}

A Declaração Universal dos Direitos Humanos (ONU, 10 de dezembro de 1948) é um marco na história dos homens, reitera uma profunda consciência acerca dos direitos universais e inalienáveis pertencentes a todo homem e a toda mulher a partir da humanidade ${ }^{1}$.

\footnotetext{
${ }^{1}$ Cf. ANDRADE, P. F. C. Cidadania e Direitos Humanos. Manuscrito, Rio de Janeiro, 2007, p. 1 .
} 
Esta Declaração constitui um marco miliar que reflete a consciência de toda a humanidade, consagrando expressamente "que o reconhecimento da dignidade inerente a todos os membros da família humana, e dos seus direitos inalienáveis e iguais, constitui o fundamento da liberdade, da justiça e da paz no mundo" (Preâmbulo) ${ }^{2}$.

Já entre os gregos e no direito romano havia a idéia da existência de uma lei natural e universal. Esse conceito e consciência foram ao longo da história se conformando. Porém foi apenas a partir do mundo Ocidental e especificamente pelo Cristianismo que a concepção de pessoa humana foi elaborada permitindo uma virada importante do paradigma jurídico centrado no dever, cuja finalidade era buscar a salvaguarda do grupo social, para um novo paradigma em que se buscou proteger o indivíduo dentro do seu grupo social e frente a este mesmo grupo ${ }^{3}$.

Ao longo da história duas Declarações foram firmadas: a Declaração da Independência dos Estados Americanos (1776), e a Declaração dos Direitos do Homem e do Cidadão (1789), cujas formulações apontavam afirmando que todos os homens nascem livres e são iguais em seus direitos ${ }^{4}$.

No caminho para estas Declarações, três momentos chamaram à atenção:

- Um primeiro quando se tratou do direito à liberdade não apenas no âmbito da expressão e liberdade religiosa mas na garantia da possibilidade da criação de agremiações, sindicatos e partidos;

- Um segundo deu-se em torno do alargamento dos grupos humanos que passaram a ser protegidos por esses direitos. Nesse processo foi concedido às mulheres e a todas as classes sociais o direito ao voto, conquista esta muito recente em muitos países ocidentais;

- Um terceiro diretamente ligado à percepção dos limites das formulações acerca dos Direitos Humanos.

Desse contexto decorreu algo importante e central para o nosso tema, isto é, a ampliação da compreensão sobre a abrangência dos Direitos dos Homens estendendo-se à promoção da igualdade dos direitos e oportunidades das áreas sociais, políticas, civis sem que haja discriminação de gênero, ou qualquer outra; e cujos direitos das mulheres e dos variados grupos étnicos foram afirmados.

\footnotetext{
${ }^{2}$ MOURA, L. D. A dignidade da pessoa e os direitos humanos. São Paulo, EDUSC, 2002, p. 10.

${ }^{3}$ Cf. ANDRADE, op. cit. p. 1.

${ }^{4}$ Cf. ibidem, p. 2.
} 
Incluiu-se os direitos relacionados à sexualidade e à liberdade de escolha pelos estilos de vida, os direitos próprios das crianças, dos idosos, dos portadores de deficiências e dos enfermos ${ }^{5}$.

Apesar da proposta dos Direitos Humanos, na sua raiz ética e na compreensão acerca da pessoa humana, ter tido sua origem no Cristianismo, inicialmente a resistência por parte da Igreja Católica e de outras Igrejas Cristãs foi grande. O Magistério da Igreja trazia muitas reservas e condenações face às afirmações dos direitos do homem na esteira da Revolução Francesa. Tal dificuldade estava na sua maior parte relacionada ao modo e ao contexto de como inicialmente surgiu à formulação filosófica dos Direitos Humanos. O contexto iluminista e anticlerical insistia em colocar o acento na liberdade religiosa e muitas vezes essa idéia estava associada a reações contra a religião e a Igreja ${ }^{6}$

Porém, posteriormente, o Magistério Eclesial apreciou, de maneira muito positiva, a Declaração Universal dos Direitos do Homem, adotada pela Assembléia Geral das Nações Unidas em 1948.

No Magistério de Pio XII já fica demonstrada uma importante mudança. Nos anos 60, através do Papa João XXIII, na Encíclica Pacem in Terris, é revelada a aceitação católica do paradigma dos Direitos Humanos.

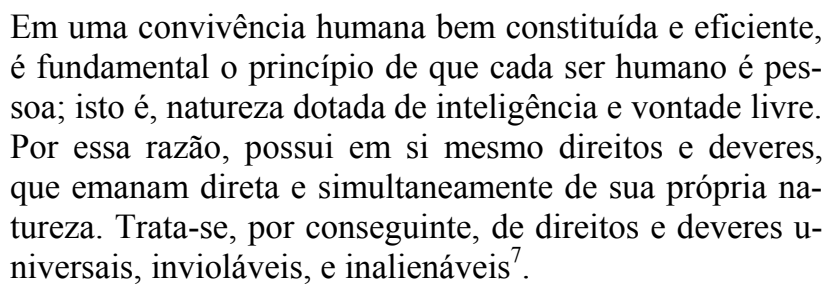

Em 1993, seguindo os pressupostos dos textos mais amplos sobre os direitos humanos, destaca-se a II Conferência Internacional de Direitos Humanos, realizada em Viena. Alguns passos importantes foram dados, quando este destacou ainda mais a complementaridade entre direitos civis/políticos e direitos econômicos/sociais/culturais, incorporando organizações nãogovernamentais e acrescentando problemáticas como as dedicadas às mulheres, às crianças ou às minorias ${ }^{8}$.

\footnotetext{
${ }^{5}$ Cf. ibidem.

${ }^{6}$ Ibidem, p. 4.

${ }^{7}$ JOÃO XXIII, Pacem in Terris, I parte, citado em: ANDRADE, op. cit., p. 6.

${ }^{8}$ Cf. VIANA, A \& LACERDA, P. Direitos e Políticas Sexuais no Brasil. O panorama atual. Rio de Janeiro, CEPESC, 2004, p. 18.
} 
Ressalvas muito importantes em relação às mulheres foram colocadas. $\mathrm{O}$ art. 38 destaca com maior abrangência,

A importância de se trabalhar no sentido de eliminar todas as formas de violência contra as mulheres na vida pública e privada, de eliminar todas as formas de assédio sexual, exploração e tráfico de mulheres, de eliminar preconceitos sexuais na administração da justiça e erradicar quaisquer conflitos que possam surgir entre os direitos das mulheres e as conseqüências nocivas de determinadas práticas tradicionais ou costumeiras, do preconceito cultural e do extremismo religioso ${ }^{9}$.

Outras Conferências aconteceram na perspectiva dos Direitos Humanos relacionados às mulheres e à sexualidade, tais como em 1975, no México; Copenhague, em 1980, e em Nairobi, em 1985, Cairo, em 1994 e Pequim em 1995, construindo um panorama diverso do que seriam as discriminações sofridas pelas mulheres ${ }^{10}$.

\section{Fundamentação dos direitos da pessoa}

Na perspectiva católica, uma eficaz interpretação dos direitos humanos depende de uma antropologia que compreenda o ser humano de maneira integral. $\mathrm{O}$ conjunto dos direitos do homem, portanto, deve corresponder à substância da dignidade da pessoa. A Igreja, através das Encíclicas Pacem in Terris e Centesimus annus empenhou-se em fornecer estes elementos essenciais $^{11}$.

\subsection{Conceito de pessoa e a dignidade humana}

O conceito de pessoa e de sua dignidade é uma herança do cristianismo. A pessoa, por sua natureza de animal racional é dotada de liberdade, revestida de uma dignidade na qual seus direitos inalienáveis estão funda$\operatorname{mentados}^{12}$.

\footnotetext{
${ }^{9}$ Ibidem, p. 20.

${ }^{10}$ Para aprofundamento, ibidem, p. 25-34.

${ }^{11}$ Cf. MARTINO, R. R. Compêndio da Doutrina Social da Igreja e Direitos da Pessoa. Atualidade Teológica, Ano IX, 2005, fasc. 20, PUC/RJ, p. 198.

${ }^{12}$ Cf. MOURA, op. cit., p. 11. 27. Para aprofundar a etimologia do termo pessoa, cf. ibidem, p. 27-29.
} 
Na Declaração Universal dos Direitos do Homem não está explicitado o conceito de pessoa, porém o mesmo é o fundamento de todas as menções feitas no artigo primeiro, quando se refere à razão e consciência de que todo ser humano é dotado na sua dignidade ${ }^{13}$.

O Papa João Paulo II, em suas Catequeses das quartas-feiras, procurou dirigir-se a quem o ouvia a refletir, a compreender e interpretar o homem naquilo que o torna essencialmente humano. Tal antropologia, integrada ou "adequada" na expressão adotada pelo Papa, não leva apenas em conta o corpo, mas considera o homem todo que se exprime através de sua corporeidade, revelando-o na realidade do ser pessoa e na sua dignidade ${ }^{14}$.

Esse homem, a quem o Papa se referia e de quem fala a Igreja, é uma pessoa concreta, somos nós, são todos os seres humanos, homens e mulheres.

"A mensagem fundamental da Sagrada Escritura anuncia que a pessoa humana é criatura de Deus (cf. Sl 139,14-18) e identifica o elemento que a caracteriza e distingue no seu ser à imagem de Deus"15.

A pessoa é unidade, não se podendo prescindir de seu caráter espiritual, intelectivo e moral. Para os existencialistas, o aspecto mais humano pertencente ao homem é o seu ex-sistere, com capacidade de se separar do determinismo do mundo e de apresentar-se na singularidade única por meio da consciência e da liberdade ${ }^{16}$.

O específico da pessoa surge bem destacado quando articula os seus dois aspectos constitutivos: a interiorização ${ }^{17}$ ou imanência e a abertura ou transcendência ${ }^{18}$.

A pessoa é relacional. Possui capacidade de abertura ao seu interior mais profundo a tudo o que está fora ou diferente dela mesma. Está aberta ao

${ }^{13}$ Cf. ibidem, p. 30-31.

${ }^{14} \mathrm{Cf}$. introdução à obra das catequeses sobre o amor humano de João Paulo II, CAFARRA, C., em: JOÃO PAULO II, Homem e Mulher o criou. Catequeses sobre o amor humano, São Paulo, EDUSC, 2005, p. 23-44.

${ }^{15}$ PONTIFÍCIO CONSELHO "JUSTIÇA E PAZ”, Compêndio da Doutrina Social da Igreja. São Paulo, Paulinas, 2005, n. 108.

${ }^{16}$ Cf. SGRECCIA, E. Manual de Bioética. Vol. 1 e 2. São Paulo, Loyola, 1996, p. 113.

${ }^{17}$ Esta entendida como a capacidade que a pessoa tem de autopossuir-se na própria vida, de escolher na sua liberdade e responsabilidade e de ser fiel a sua própria identidade enquanto ser humano. Cf. GARCÍA RUBIO, A. O Chamado de Deus à Vida: vocação integral do ser humano e suas várias dimensões. Cadernos de Doutrina Social da Igreja, Rio de Janeiro, vol. $1,2005$.

${ }^{18}$ Cf. idem, Unidade na Pluralidade. O ser humano à luz da fé e da reflexão cristãs. 3. ed. rev. e ampliada. São Paulo, Paulus, 2001, p. 304-307, completar com PONTIFÍCIO CONSELHO “JUSTIÇA E PAZ”, op. cit, n. 130-131. 
mundo através das relações sociais e políticas mediante o amor, a solidariedade, o diálogo. Aberta a Deus, à justiça e ao bem.

Para uma adequada visão de pessoa humana, as dimensões do "ser pessoa" devem estar integradas. Se isto não for vivido, certamente podemos cair num empobrecimento da sua expressividade, que poderá afetar o conjunto da vida cristã.

Jesus de Nazaré viveu integralmente e sadiamente estas dimensões em toda a sua complexidade, manifestando o que podemos chamar de subjetividade aberta. Daí nos chamou e capacitou, como cristãos a vivê-la também. Ele é o Modelo, é o Mestre, é o Caminho para isso ${ }^{19}$.

\subsection{Gênero e a "antropologia da diferença"}

O gênero deve ser compreendido como o conjunto de relações, atributos, papéis, crenças e atitudes que definem o que significa ser homem ou ser mulher. É um elemento constitutivo das relações sociais entre homens e mulheres, partindo de uma construção social e histórica.

A base dessa construção parte de símbolos, normas e instituições que irão definir modelos de masculinidade e feminilidade e padrões de comportamento aceitáveis ou não. O gênero é um importante delineador dos campos de atuação para cada sexo, dando suporte à elaboração de leis e suas formas de aplicabilidade ${ }^{20}$.

O homem e a mulher têm a mesma dignidade e são de igual nível e valor, não só porque ambos, na sua diversidade, são imagem de Deus, mas ainda mais profundamente porque é imagem de Deus o dinamismo de reciprocidade que anima o nós do casal humano ${ }^{21}$.

A diversidade ou a diferença entre homem e mulher é inegável e já conhecidas, e esta constatação é muito anterior à noção de gênero.

Na reflexão sobre as relações de gênero refletir sobre o "diferente" é de fundamental importância.

Há uma unicidade e interna diversidade entre tudo o que é criado. A física tem nos ensinado muito em relação ao microcosmo presente num grande macrocosmo. A interação, a ligação em rede é perfeita e inegável.

\footnotetext{
${ }^{19}$ Cf. GARCÍA RUBIO, A., O chamado de Deus à Vida, op. cit., p. 5.7.

${ }^{20}$ Cf. MINISTÉRIO DA SAÚDE. Politica Nacional de Atenção Integral à Saúde da Mulher (PAISM). Princípios e Diretrizes. Brasília, DF, 2004, p. 12.

${ }^{21}$ PONTIFÍCIO CONSELHO “JUSTIÇA E PAZ”, op. cit,, n. 111, acrescentar ns. 112-113.
} 
Captar, perceber mesmo as centelhas desse mistério significa já começar a apreender a diferença como algo inerente a todo ser vivo. Tudo o que existe é diferente e possui uma marca inconfundível que revela a verdadeira criatividade e originalidade do $\operatorname{ser}^{22}$.

Esse diferente está em relação; está sempre "junto com", e só existe porque está em relação com o outro, que marca a sua diferença. O surpreendente é que a unidade do universo, a unidade entre as pessoas existe e se constrói porque há uma acolhida profunda da diferença. Esse mistério perpassa a questão dos gêneros masculino e feminino ${ }^{23}$.

Aceitar a diferença é aceitar a dialética da distância e da proximidade.

Quando assumimos a diferença, assumimos também a semelhança e a igualdade; consentimos com uma vida de comunhão e autonomia que não é capaz de anular o outro como pessoa.

A antropologia da diferença tem uma grande força, porque está em nós. Com essa percepção, apreendemos em nós algumas dimensões e características que não podem ser anuladas e nem deformadas pelo outro ${ }^{24}$.

\section{Políticas públicas de saúde e a questão de gênero}

Na população brasileira $50,77 \%$ são mulheres e estas são as principais usuárias do Sistema Único de Saúde (SUS), freqüentam os serviços de saúde para atendimento próprio ou no acompanhamento de outros usuários, como crianças, familiares em geral, idosos, etc.

A situação de saúde, especificamente tratada neste ítem, envolve vários aspectos da vida, porém no caso das mulheres, há um notório agravamento dos problemas em decorrência da discriminação nas relações de trabalho e a sobrecarga de responsabilidades impostas pelo trabalho doméstico. Somadas a estes problemas há outras variáveis como raça, etnia, situação de pobreza e exclusão social. Embora estatisticamente as mulheres vivam mais do que os homens, estas se mostram mais vulneráveis em sua saúde, adoecendo com maior freqüência.

O Ministério da Saúde, na busca de melhorar a compreensão e definir a especificidade no seu atendimento criou os Programas de Atenção à Saúde, e dentre estes o de Atenção à Saúde da Mulher. Seu objetivo principal é de

${ }^{22}$ Cf. GEBARA, I., Conhece-te a ti mesma, São Paulo, Paulus, 1991, p. 39.

${ }^{23}$ Cf. ibidem.

${ }^{24}$ Ibidem, p. 42; e complementar com: cf. GARCÍA RUBIO, A., Nova Evangelização e Maturidade Afetiva, 2. ed. São Paulo, Paulinas, 1993, p. 73. 
propor diretrizes para a humanização e a qualidade do atendimento à população feminina nas diversas fases de sua vida. ${ }^{25}$

Atualmente está em vigor o Programa de Assistência Integral à Saúde da Mulher (PAISM) desde 2004 com abrangência até 2008. Este tem caráter nacional, no contexto da reforma sanitária brasileira.

\subsection{Saúde da mulher e reforma sanitária no Brasil}

Até a década de 1970, a saúde das mulheres era vista pelas políticas públicas de saúde, apenas na perspectiva procriativa, direcionando o cuidado para o ciclo gravídico-puerperal. Havia muitas lacunas, e a mulher era reconhecida apenas como mãe, por exemplo, a saúde da mulher trabalhadora era atendida em vista do que poderia ser nocivo ao processo reprodutivo.

Os Programas de Saúde até então eram verticais faltando integração com os demais programas e ações sociais propostas pelo Governo Federal. As metas eram definidas de maneira centralizada, sem qualquer avaliação ou participação das populações locais.

Este quadro vai perdurar até a reforma sanitária nos anos 80 , quando começa um tempo de grande efervescência da saúde no Brasil, propiciando um significativo aumento da participação das mulheres nas decisões relacionadas à gestão da saúde. Nesse contexto foi relevante a presença do movimento feminista ${ }^{26}$.

Fortemente criticado pelo movimento das mulheres o programa foi revisto, frente às desigualdades nas condições de vida e nas relações entre os homens e as mulheres, quanto aos problemas ligados à sexualidade e à reprodução, as dificuldades pertinentes à contracepção, as DST's, a sobrecarga pelo trabalho doméstico e a criação dos filhos ${ }^{27}$.

"A criação dos PAISM, em 1983, representou um marco na história das políticas públicas voltadas às mulheres"28.

O PAISM incorporou como princípios e diretrizes as propostas de descentralização, hierarquização e regionalização dos serviços, atendendo a integralidade e equidade da atenção.

O novo programa para a saúde da mulher incluía ações educativas, preventivas, de diagnóstico, tratamento e

\footnotetext{
${ }^{25}$ Cf. MINISTÉRIO DA SAÚDE, op. cit, p. 9-10.

${ }^{26}$ Cf. COSTA, A M \& Outros (Org.). Saúde, Equidade e Gênero. Brasília, Editora Universidade de Brasília, 2000, p. 181.

${ }^{27}$ Cf. MINISTÉRIO DA SAÚDE, op. cit., p. 15-16.

${ }^{28}$ COSTA, op. cit., p. 185.
} 
recuperação, englobando a assistência à mulher em clínica ginecológica, no pré-natal, parto e puerpério, no climatério, em planejamento familiar, DST, câncer de colo de útero e de mama, além de outras necessidades identificadas a partir do perfil populacional das mulheres ${ }^{29}$.

Após cuidadoso balanço realizado no período de 1998 a 2002, percebeu-se que muito se trabalhou na resolução dos problemas, priorizando-se a saúde reprodutiva especialmente sobre os dados dos índices de mortalidade materna. Essa perspectiva acabou por comprometer a transversalidade de gênero e raça, apesar de se notar um avanço no sentido da integralidade e uma ruptura com as ações verticalizadas do passado, uma vez que os problemas não foram abordados de maneira isolada.

Nesse balanço algumas necessidades ficaram claras, algumas lacunas estavam muito evidentes em relação aos programas anteriores. Assim sendo a gestão 2004-2008 propõe como acréscimo atender à mulher nas fases de climatério/menopausa; nas suas queixas ginecológicas; infertilidade e reprodução assistida; saúde da mulher adolescente; nas doenças crônicodegenerativas; na saúde ocupacional; saúde mental; doenças infectocontagiosas e a inclusão das questões de gênero e raça nas ações a serem desenvolvidas ${ }^{30}$.

\section{2. Ética e relações de gênero}

Como já visto a perspectiva de gênero permite um grande salto qualitativo na discussão da equidade nas políticas públicas, especialmente na saúde. A especificação de gênero permite o desmascaramento das desigualdades sociais, muitas vezes de uma sociedade preconceituosa, discriminadora, e profundamente injusta, quando a Constituição rege uma sociedade justa, livre e solidária.

A pessoa humana não pode e não deve ser instrumentalizada por estruturas sociais, econômicas e políticas, pois todo homem tem a liberdade de orientar-se para o seu fim último. Por outro lado, toda a realização cultural, social, econômica e política, em que atuam historicamente a sociabilidade da pessoa e a sua atividade transformadora do universo, deve ser sempre considerada também no seu

\footnotetext{
${ }^{29}$ MINISTÉRIO DA SAÚDE, op. cit., p. 17.

${ }^{30}$ Cf. ibidem, p. 19.
} 
aspecto de realidade relativa e provisória, porque "a figura desse mundo passa!" $(1 \text { Cor } 7,31)^{31}$.

Tratando-se de gênero o foco volta-se para as desigualdades sofridas pelas mulheres, mas também lança luz sobre a desigualdade social como um todo. No contexto dos excluídos estão também as mulheres, onde a exclusão por vezes mostra-se perversa.

A partir das distinções existentes entre os homens e as mulheres podese adotar providências adequadas, ora a prática de providências específicas, ora a proibição de tratamento discriminatório, ora a implementação de caminhos para a equidade ${ }^{32}$.

A abordagem sobre o gênero constitui uma das mais imprescindíveis contribuições para "desnaturalizar" e problematizar os fenômenos e os fatores ligados ao processo saúde-doença. A literatura tem sido testemunha de que determinados comportamentos, tanto presente nos homens, quanto nas mulheres, baseados em padrões hegemônicos de masculinidade e feminilidade, são provocadores de sofrimento, adoecimento e morte. ${ }^{33}$

Não se pode perder de vista que a justiça de uma sociedade e de uma cultura é medida pelo respeito à dignidade do ser humano. A ordem social e o seu progresso devem estar ordenados aos bem das pessoas; o próximo deve ser percebido como um "outro eu", sem nenhuma exceção. Assim todos os programas sociais, científicos e culturais devem ser orientados pela consciência do primado de cada ser humano.

Cultura alguma está autorizada a instrumentalizar a pessoa para fins alheios, para projetos de caráter econômico, social e político impostos por quaisquer que sejam ${ }^{34}$.

O relatório sobre a situação da População Mundial (2002) mostra que o número de mulheres que vivem em situação de pobreza é superior ao de homens; que as mulheres trabalham um volume maior de horas/dia; e que metade de seu tempo são gastos em atividades não remuneradas, diminuindo assim seu acesso aos bens sociais e aos serviços de saúde. Aparece claramente nas leis, na política e nas práticas sociais o desequilíbrio de gênero.

Infelizmente ainda vivemos uma relação de gênero muito desigual, onde a diferença entre os sexos é legitimada em nome de um determinismo biológico da superioridade de um dos sexos, no caso pelo homem.

\footnotetext{
${ }^{31}$ PONTIFÍCIO CONSELHO “JUSTIÇA E PAZ”, op. cit., n. 48.

${ }^{32}$ Cf. COSTA, op. cit., p. 301-303.

${ }^{33}$ Cf. MINISTÉRIO DA SAÚDE, op. cit., p. 16.19

${ }^{34}$ Cf. PONTIFÍCIO CONSELHO, op. cit., n. 132-134.
} 
Compreender as relações de gênero requer uma leitura das origens do patriarcalismo, herança presente nas mentalidades e ações humanas ${ }^{35}$. Portanto é impossível de uma hora para outra desconstruir uma mentalidade que vigorou por séculos, inclusive entre os muros da Igreja. Por outro lado não se pode aceitar e nem ser conivente com tal mentalidade ajudando-a a mantê-la.

A ética cristã vai apontar sempre para a necessária relacionalidade a partir da realidade existencial de que homem e mulher são criados à Imagem e Semelhança de Deus. A alteridade é o dado "chave" para toda discussão nas relações de gênero e a superação das suas deficiências.

A mulher "perfeita" não e aquela que anula os elementos atribuídos à masculinidade, mas aquela que os integra, sem perder a feminilidade. O varão "perfeito" não é aquele que anula os elementos atribuídos à feminilidade, mas aquele que os integra em si, sem perder sua masculinidade... O varão e a mulher se fazem um sob o olhar do outro, e isto também no plano social ${ }^{36}$.

\section{Questões de ordem social e pastoral}

É fato de que "Deus não faz acepção de pessoas" (At 10,34). Todos os homens e mulheres são dotados de uma mesma dignidade, pois são criaturas, criadas à Imagem e Semelhança de Deus (cf. Gl 3,28).

Posto que no rosto de cada homem resplandece algo da glória de Deus, a dignidade de cada homem diante de Deus é o fundamento da dignidade do homem perante os outros homens. Este é o fundamento último da radical igualdade e fraternidade entre os homens, independentemente da sua raça, nação, sexo, origem, cultura e classe ${ }^{37}$.

Infelizmente ainda podemos encontrar ranços de discriminação em alguns setores sociais ou em algumas práticas pastorais, e isto se dá por conta da falta de conhecimento do que venha a ser o gênero. A mulher continua sofrendo os embates de inferioridade impostos ao longo dos séculos. Muito se avançou, se reviu, porém ainda há muito para se reparar e conquistar.

\footnotetext{
${ }^{35}$ Para aprofundar o contexto histórico do patriarcalismo e sua evolução, cf. MO SUNG, J., Conversando sobre Ética e Sociedade. Petrópolis, Vozes, p. 95-107.

${ }^{36}$ MOSER, A., O Enigma da Esfinge. A Sexualidade. Petrópolis, Vozes, 2001, p.199.

${ }^{37}$ PONTIFÍCIO CONSELHO “JUSTIÇA E PAZ”, op. cit., n. 144.
} 
Conforme vimos, o Magistério Eclesial através da doutrina social tem uma palavra muito animadora, porém a práxis precisa ser mais aproximada do verbo.

Somente através do reconhecimento da dignidade humana é que se pode chegar ao crescimento comum e pessoal de todos os seres humanos.

\section{Conclusão}

A fé cristã é clara e corajosa quando aponta o caminho para um discernimento verdadeiro na discussão pertinente ao gênero. As relações devem ser construídas de maneira integrada e no amor. A sexualidade, a relação dos gêneros nos chama a "ser para o outro" implicando reconhecer a história do outro, seus projetos, anseios, sentimentos e também seus limites. O outro deve encontrar espaço e liberdade para ser verdadeiramente ele mesmo ${ }^{38}$.

A teologia está comprometida na colaboração e no diálogo acerca da direção e orientação dos costumes humanos a partir de um discernimento criterioso em consonância com a escuta da Palavra de Deus, do conselho do Magistério Eclesial e da defesa de uma visão integrada do homem enraizada na história de seu tempo ${ }^{39}$.

O acolhimento de Jesus Cristo, através do seu discipulado, será sempre o caminho indispensável para todo e qualquer discernimento ético e decorrente práxis.

Cássia Quelho Tavares

Doutoranda em Teologia PUC/RJ Professora do Departamento de Teologia PUC/RJ

\footnotetext{
${ }^{38}$ Cf. HÄRING, B. Livres e Fiéis em Cristo: Teologia Moral para sacerdotes e leigos. Vol. II: A Verdade vos libertará. São Paulo, Paulinas, 1982, p. 489-491.

${ }^{39}$ Cf. JOÃO PAULO II. Carta Encíclica Veritatis Splendor. 2. ed. São Paulo, Paulinas, 1993, n. 4.
} 